\title{
Polymorphism of the promoter region and exon 1 of the CTLA4 gene in endemic pemphigus foliaceus (fogo selvagem)
}

D.P. Pavoni ${ }^{1}$,

L.B. Cerqueira ${ }^{1}$,

V.M.M.S. Roxo ${ }^{1}$ and M.L. Petzl-Erler ${ }^{1}$
${ }^{1}$ Laboratório de Genética Molecular Humana, Universidade Federal do Paraná, Curitiba, PR, Brasil

\section{Correspondence}

M.L. Petzl-Erler

Departamento de Genética

Universidade Federal do Paraná

81531-990 Curitiba, PR

Brasil

Fax: +55-41-3266-2042

E-mail: perler@ufpr.br

The present address of D.P. Pavoni is Instituto de Biologia Molecular do Paraná, Curitiba, PR, Brasil.

Research supported by CNPq, Fundação Araucária and CAPES

Received August 19, 2005 Accepted July 14, 2006

\begin{abstract}
Endemic pemphigus foliaceus (EPF) is an autoimmune bullous skin disease characterized by acantholysis and antibodies against a desmosomal protein, desmoglein 1. Genetic and environmental factors contribute to development of this multifactorial disease. HLA class II and some cytokine gene polymorphisms are the only genetic markers thus far known to be associated with susceptibility to or protection from EPF. The cytotoxic T-lymphocyte antigen-4 gene (CTLA4) encodes a key immunoreceptor molecule that regulates and inhibits Tcell proliferation. It participates in the regulatory process controlling autoreactivity and therefore has been considered a strong candidate gene in autoimmune diseases. In the search for genes that might influence EPF pathogenesis, we analyzed variants of the CTLA4 gene in a sample of 118 patients and 291 controls from a Brazilian population. This is the first study investigating the possible role of polymorphisms of the $2 \mathrm{q} 33$ chromosomal region in differential susceptibility to pemphigus foliaceus. Promoter region and exon 1 single nucleotide polymorphisms $-318(C, T)$ and $49(A, G)$ were genotyped using sequence-specific oligonucleotide probes after amplification by the polymerase chain reaction. The allelic and genotypic frequencies did not differ significantly between the patient and the control groups (-318T: 9.8 and 10.9\%, 49G: 33.0 and $35.2 \%$ were the allelic frequencies in patients and controls, respectively). In addition, no significant difference was found when the patient and control population samples were stratified by the presence of $H L A-D R B 1$ alleles. We conclude that the CTLA4 -318 $(C, T)$ and $49(A, G)$ polymorphisms do not play a major role in EPF development.
\end{abstract}

\section{Introduction}

Pemphigus foliaceus is an autoimmune disease characterized by antibodies against the desmosomal protein desmoglein 1 and
Key words

- CTLA4

- Pemphigus

- Fogo selvagem

- Autoimmunity

- Genetic susceptibility

- Brazilian population 
phigus foliaceus, in South America the disease has a particular epidemiology, being concentrated in some geographic areas, mainly in central Brazil. Therefore, it is usually referred to as endemic pemphigus foliaceus (EPF). It is also known in Brazil as fogo selvagem (wild fire) (for a review, see Ref. 1).

EPF is a multifactorial trait. With the exception of the HLA-DRBI and $D Q$ (2-4) polymorphisms, and of the IL6 and possibly the IL4 polymorphisms (5), the genetic factors influencing the pathogenesis of EPF remain largely unknown. Analysis of polymorphisms of the cytokine and cytokine receptor genes TNF, LTA, IL1A, IL1B, ILIRN, $I L 4 R$, and ILIO revealed no significant associations with $\operatorname{EPF}(5,6)$.

The cytotoxic $\mathrm{T}$ lymphocyte antigen- 4 (CTLA-4) protein, coded by the CTLA4 (CD152) gene, is a negative regulator of the $\mathrm{T}$ lymphocyte immune response of prime importance to immunological homeostasis. CTLA-4 down-regulates $T$ cell activation through an as yet not fully understood mechanism. This immune attenuator participates in the regulatory process controlling autoreactivity (7).

There are only speculations about how CTLA4 polymorphisms could modulate the function of the molecule in vivo. However, several studies have established a connection between certain CTLA4 single nucleotide polymorphisms (SNPs) and microsatellite variants and differences in the mRNA and protein expression, and the immune response (8-13). The consensus arising from these investigations is that decreased expression and lower efficiency of CTLA-4 are associated with alleles $-318 C, 49 G$, and with a high number of AT repeats (28 or more) for the $(\mathrm{AT})_{\mathrm{n}}$ microsatellite located in the 3' untranslated region of the last exon.

CTLA4 variants have been associated with several autoimmune diseases, such as type 1 diabetes mellitus, Graves' disease, autoimmune thyroiditis, Addison's disease, and systemic lupus erythematosus, among oth- ers (reviewed in Ref. 14; meta-analysis for systemic lupus erythematosus in Ref. 15). The role of CTLA-4 in immunosuppression and the coincidence of different autoimmune diseases in some families and individuals have led some researchers to suggest that particular variants of some genes, including CTLA4, may predispose to autoimmunity in general $(16,17)$. Notwithstanding the considerable evidence of a role for CTLA4 polymorphism in autoimmune disease pathogenesis, the effect of the susceptible alleles or genotypes is generally low and several studies have not revealed any significant associations $(18,19)$.

Since the genetic component of EPF disease susceptibility is poly- or oligogenic, in the search for genes whose variants could modulate EPF development, we analyzed two SNPs of the CTLA4 gene. We compared their frequencies between patients and controls to test the hypothesis of involvement of this gene's variability in the interindividual variation of susceptibility to the disease.

\section{Material and Methods}

A total of 118 patients and 291 healthy individuals (controls) from an ethnically admixed population were analyzed. The population studied is extensively admixed but is not panmictic. Therefore, the different population strata may differ regarding allelic frequencies. Since there was interest in association analysis in the subpopulations and since there was the need to match the patient and control samples for ancestry, individuals were classified according to facial morphological characteristics. This classification is a proxy to an estimate of the relative contribution of European and African ancestry to each individual's genome. Classification was based on shape of the nose, mouth, and eyes, hair type, and skin color. Among the patients, $55 \%$ were Euro-Brazilians, $42 \%$ were Mulattos and 3\% were not classified. Among controls, $75 \%$ were Euro-Brazilians, 
$22 \%$ were Mulattos and 3\% were not classified. Blood samples of patients and controls were collected in the States of Mato Grosso do Sul and Paraná. Diagnosis was based on clinical criteria, histopathology and indirect immunofluorescence. Information was obtained with a questionnaire and an interview. The control and patient groups were similar for birthplace and place of residence, socioeconomic status, gender prevalence, age distribution, and occupation. All individuals were unrelated. The study was approved by the Human Subjects Research Ethics Committee, according to Brazilian Federal laws and all individuals gave written informed consent to participate in the study.

DNA extraction was performed by standard salting-out and phenol-chloroform methods. To amplify the DNA segment including the promoter (-318 position from the ATG start codon, $\mathrm{C}$ or $\mathrm{T}$ ) and exon 1 (49 position, codon 17, A or G) SNPs, a nested PCR was performed. The primers used in the first reaction were 5'-GGATTTAGGAGGACC CTTGTA-3' (forward primer) and 5'-AAA CACCTCCTCCATCTTCAT-3' (reverse primer). In the second reaction, the same forward primer was used and the reverse primer was 5'-CTTTGCAGAAGACAGGG ATGAA-3'. Typings were performed after hybridization with non-radioactive (biotin or digoxigenin) labeled probes: for the promoter variants, 5'-AGATCCTCAAAGTGA3' and 5'-AGATCCTTAAAGTGA-3'; for exon 1 variants, 5'-CCTGGCTACCAGGAC3' and 5'-CCTGGCTGCCAGGAC-3'.

Genotypic, allele carrier and allelic frequencies for each SNP were obtained by counting. Allele carriers are the individuals presenting the allele (or the SNP variant) in either the homozygous or the heterozygous state. The frequency of the cis combinations of -318 and 49 variants (CTLA4 haplotypes, which correspond to alleles of the CTLA4 gene, as opposed to alleles - or variants - of each SNP) was estimated using the expectation-maximization algorithm of the ARLEQUIN software package, version 2.000 (20). The same software was used to evaluate the fit to the Hardy and Weinberg equilibrium expectations according to the procedure described by Guo and Thompson (20).

Comparisons between the frequencies observed in the patient and control groups and between the population strata of different ancestry (Euro-Brazilian; Mulatto) were performed by analysis of contingency tables using Fisher's exact test via the Metropolis Algorithm, using the $\mathrm{R} \times \mathrm{C}$ computational program (21).

The odds ratio (OR) was calculated to estimate the magnitude of the difference in frequency between the patient and the control groups. The $95 \%$ confidence interval (CI) of the OR was calculated using the formula:

$\mathrm{CI}(95 \%)=\operatorname{anti} \ln \left(\ln (\mathrm{OR}) \pm 1.96 \sqrt{\frac{1}{a}}+\frac{1}{b}+\frac{1}{c}+\frac{1}{d}\right)$

Association analysis was performed for each SNP separately and for the alleles of the gene (that is, the CTLA4 haplotypes). Allele carrier and genotypic frequencies were compared between the patient and control samples, and between the subsamples stratified according to ancestry and to diseaseassociated $H L A-D R B 1$ alleles. One hundred and five patients and 135 controls had been previously typed for $H L A-D R B 1$ (4). This subsample was used to test for possible interactions between the CTLA4 and HLA$D R B 1$ genes regarding EPF disease susceptibility.

\section{Results}

The CTLA4 alleles (that is, the cis combinations of variants of the two SNPs) were named $C A, C G, T A$, and $T G$. Allele $T G$ was not found in this population sample; consequently linkage disequilibrium between the -318 and 49 SNP was the maximum possible $\left(D^{\prime}=1\right)$. 
Genotypic frequencies among patients and controls were in Hardy-Weinberg equilibrium (Table 1).

The differences between patients and controls regarding the allele carrier, allelic and genotypic frequencies for each CTLA4 SNP and for the cis combinations of variants of the two SNPs (CTLA4 alleles, or haplotypes) were not statistically significant either for each population stratum individually (Euro-Brazilians, Mulattos; data not shown), or for the whole sample of patients and controls (Table 1).

Since there was no statistical difference between patients and controls and between Euro-Brazilians and Mulattos regarding the -318 and 49 SNP frequencies, we used the whole sample to estimate the allelic frequencies in this Brazilian population: $89.5 \%$ for $-318 C ; 10.5 \%$ for $-318 T ; 65.4 \%$ for $49 A$, and $34.6 \%$ for $49 G$.

\begin{tabular}{|c|c|c|c|c|c|}
\hline $\begin{array}{l}\text { Genotype or allele } \\
\text { carrier status }\end{array}$ & $\begin{array}{l}\text { Patients } \\
(\mathrm{N}=118)\end{array}$ & $\begin{array}{l}\text { Controls } \\
(\mathrm{N}=291)\end{array}$ & $\mathrm{P}$ & OR & $95 \% \mathrm{Cl}$ \\
\hline$C A / C A$ & $42(34.8 \%)$ & $76(23.6 \%)$ & $0.121^{a}$ & 1.0 & \\
\hline$C A / C G$ & $38(32.6 \%)$ & $121(48.5 \%)$ & & 0.57 & $0.34-0.96$ \\
\hline$C A / T A$ & 13 (9.9\%) & $41(10.3 \%)$ & & 0.57 & $0.28-1.19$ \\
\hline$C G / C G$ & $15(15.1 \%)$ & 35 (12.7\%) & & 0.78 & $0.38-1.58$ \\
\hline$C G / T A$ & $10(7.6 \%)$ & $14(4.2 \%)$ & & 1.29 & $0.53-3.16$ \\
\hline$T A / T A$ & $0(0 \%)$ & $4(0.6 \%)$ & & NC & $\mathrm{NC}$ \\
\hline$-318 C / C$ & 95 (80.5\%) & $232(79.7 \%)$ & $0.662^{a}$ & 1.0 & \\
\hline$-318 \mathrm{C} / \mathrm{T}$ & $23(19.5 \%)$ & $55(18.9 \%)$ & & 1.02 & $0.59-1.76$ \\
\hline$-318 \mathrm{~T} / \mathrm{T}$ & $0(0 \%)$ & $4(1.4 \%)$ & & NC & NC \\
\hline $49 A / A$ & $55(46.6 \%)$ & $121(41.6 \%)$ & $0.583^{a}$ & 1.0 & \\
\hline $49 A / G$ & $48(40.7 \%)$ & $135(46.4 \%)$ & & 0.78 & $0.49-1.24$ \\
\hline $49 \mathrm{G} / \mathrm{G}$ & $15(12.7 \%)$ & $35(12.0 \%)$ & & 0.94 & $0.48-1.87$ \\
\hline$-318 C$ & $118(100.0 \%)$ & 287 (98.6\%) & 0.584 & NC & NC \\
\hline$-318 T$ & $23(19.5 \%)$ & $59(20.3 \%)$ & 0.894 & 0.95 & $0.56-1.63$ \\
\hline $49 A$ & 103 (87.3\%) & $256(88.0 \%)$ & 0.873 & 0.94 & $0.49-1.79$ \\
\hline $49 G$ & $63(53.4 \%)$ & 170 (58.4\%) & 0.373 & 0.82 & $0.53-1.25$ \\
\hline
\end{tabular}

Data are reported as number of patients or controls with percent in parentheses. Hardy-Weinberg equilibrium test result for the -318 SNP (Patients: $P=0.598$, Controls: $\mathrm{P}=0.758$ ), the 49 SNP (Patients: $\mathrm{P}=0.406$, Controls: $\mathrm{P}=0.898$ ) and the $C T L A 4$ alleles (Patients: $P=0.365$, Controls: $P=0.077$ ). a $P$ value for the genotypic frequency distribution; $\mathrm{OR}=$ odds ratio; $\mathrm{Cl}=$ confidence interval; $\mathrm{NC}=$ not calculated.
Even if variants of a gene are not individually associated with a phenotypic trait, they still may have an effect in combination with alleles or genotypes of other genes (gene interaction). In order to identify interactions between the CTLA4 and HLA-DRBI genes, we analyzed the frequency of CTLA4 variants in the sample stratified according to $D R B 1$ alleles known to be associated with EPF (4). The subsamples analyzed were positive for the DR1 allele group (64 patients and 24 controls), for the DR4 allele group (39 patients and 28 controls), for the $D R B 1 * 0101$ allele ( 25 patients and 15 controls), and for the DRB1*0102 allele (36 patients and 9 controls). These allele groups and alleles are all positively associated with $\mathrm{EPF}(\mathrm{OR}=7.4$, 2.7, 1.8, and 10.4, respectively). For the other HLA-DRB1 alleles associated with EPF (4), the subsamples were too small for statistical comparison. In none of the subsamples analyzed did the CTLA4 frequencies differ significantly between patients and controls (data not shown). This indicates absence of gene interaction. However, this result should be interpreted with caution since the statistical power of the test was low due to the small subsample sizes.

\section{Discussion}

Two CTLA4 SNPs were analyzed in this study: $-318(C, T)$ of the promoter region and $49(A, G)$ in the first exon, which leads to an amino acid variation (Thr $\leftrightarrow$ Ala) at position 17 (T17A) in the leader sequence $(22,23)$. Both have been extensively analyzed in numerous autoimmune diseases and several significant associations have been reported (see Introduction).

In the present study, no statistically significant association between EPF and variants of the CTLA4 gene was observed. The frequencies of the SNP variants, SNP variant carriers, SNP genotypes, CTLA4 alleles, CTLA4 allele carriers, and CTLA4 genotypes did not differ significantly between 
EPF patients and controls.

The frequencies of -318 and 49 variants observed in this study are similar to the published frequencies for European and European-derived populations, which roughly range from 62 to $73 \%$ for $49 A$ and from 87 to $90 \%$ for $-318 C(23-25)$. This is in agreement with historical records and the phenotypic characteristics of the population sample, which show that the population studied is of predominantly European origin (see Material and Methods).

Linkage disequilibrium between SNPs -318 and 49 has been demonstrated before (26) and in our sample, the maximum possible linkage disequilibrium was observed. This results from absence of the $T G$ cis combination, i.e., the $-318 T$ variant occurs only in combination with $49 A$ (resulting in the CTLA4 TA allele).

The present study did not reveal an influence of the CTLA4 -318 or 49 polymorphisms in the etiopathogenesis of pemphigus foliaceus. This result does not support the hypothesis that genetic variation of CTLA-4 confers susceptibility to autoimmunity in general (17). In fact, although variants of SNPs -318 and 49 and of the $(\mathrm{AT})_{\mathrm{n}}$ microsatellite in the 3'UT region of exon 4 have been correlated with several autoimmune diseases, a number of studies did not detect significant associations (see Introduction). Moreover, there is no consensus about the primary risk allele(s) or haplotype(s) contributing to disease susceptibility and to the observed effect on $\mathrm{T}$ cell activation. This is due to the strong linkage disequilibrium among these three markers. Two recent publications analyzing numerous polymorphic markers of chromosome 2 q33, encompassing the CD28, CTLA4 and ICOS genes indicated that there may be other susceptibility markers in this genomic region and that those probably differ among diseases. Polymorphisms in a noncoding region downstream of the CTLA4 gene (13) were associated with autoimmune endocrinopathies (Graves' disease, autoimmune hypothyroidism, type 1 diabetes), while markers closer to CD28 and to ICOS but not CTLA4 markers were associated with multiple sclerosis in a two-stage study of the Finnish population (18).

We conclude that the CTLA4 polymorphisms at positions -318 and 49 do not play a major role in EPF development. Also, there is no evidence of $H L A-D R B 1$ and CTLA4 gene interaction. Nevertheless, the lack of significant associations with promoter and exon 1 variants does not rule out the possibility that genetic variability of CTLA may have a role in EPF development. The present report is the first on the $2 \mathrm{q} 33$ chromosomal region markers in EPF. In view of the function of CTLA4 and closely linked genes $(C D 28, I C O S)$ in the regulation of the $\mathrm{T}$ cell responses and of the possible functional relevance of polymorphisms in this region, we suggest further analysis of additional polymorphic markers located in this genomic region.

\section{Acknowledgments}

We thank patients and control individuals for their collaboration. The staff of the Hospital Adventista do Pênfigo is kindly acknowledged for hospitality and information.

\section{References}

1. Hans-Filho G, Aoki V, Rivitti E, Eaton DP, Lin MS, Diaz LA. Endemic pemphigus foliaceus (fogo selvagem) - 1998. The Cooperative Group on Fogo Selvagem Research. Clin Dermatol 1999; 17: 225235.

2. Petzl-Erler ML, Santamaria J. Are HLA class II genes controlling susceptibility and resistance to Brazilian pemphigus foliaceus (fogo selvagem)? Tissue Antigens 1989; 33: 408-414.

3. Moraes ME, Fernandez-Vina M, Lazaro A, Diaz LA, Filho GH, Fried$\operatorname{man} \mathrm{H}$, et al. An epitope in the third hypervariable region of the DRB1 gene is involved in the susceptibility to endemic pemphigus 
foliaceus (fogo selvagem) in three different Brazilian populations. Tissue Antigens 1997; 49: 35-40.

4. Pavoni DP, Roxo VM, Marquart Filho A, Petzl-Erler ML. Dissecting the associations of endemic pemphigus foliaceus (fogo selvagem) with HLA-DRB1 alleles and genotypes. Genes Immun 2003; 4: 110116.

5. Pereira NF, Hansen JA, Lin MT, Roxo VM, Braun K, Petzl-Erler ML. Cytokine gene polymorphisms in endemic pemphigus foliaceus: a possible role for IL6 variants. Cytokine 2004; 28: 233-241.

6. Roxo VM, Pereira NF, Pavoni DP, Lin MT, Hansen JA, de O Poersch $\mathrm{C}$, et al. Polymorphisms within the tumor necrosis factor and lymphotoxin-alpha genes and endemic pemphigus foliaceus - are there any associations? Tissue Antigens 2003; 62: 394-400.

7. Chikuma S, Bluestone JA. CTLA-4 and tolerance: the biochemical point of view. Immunol Res 2003; 28: 241-253.

8. Huang D, Giscombe R, Zhou Y, Pirskanen R, Lefvert AK. Dinucleotide repeat expansion in the CTLA-4 gene leads to $T$ cell hyperreactivity via the CD28 pathway in myasthenia gravis. J Neuroimmunol 2000; 105: 69-77.

9. Kouki T, Sawai Y, Gardine CA, Fisfalen ME, Alegre ML, DeGroot LJ. CTLA-4 gene polymorphism at position 49 in exon 1 reduces the inhibitory function of CTLA-4 and contributes to the pathogenesis of Graves' disease. J Immunol 2000; 165: 6606-6611.

10. Ligers A, Teleshova N, Masterman T, Huang WX, Hillert J. CTLA-4 gene expression is influenced by promoter and exon 1 polymorphisms. Genes Immun 2001; 2: 145-152.

11. Maurer M, Loserth S, Kolb-Maurer A, Ponath A, Wiese S, Kruse N, et al. A polymorphism in the human cytotoxic T-lymphocyte antigen 4 (CTLA4) gene (exon $1+49$ ) alters T-cell activation. Immunogenetics 2002; 54: 1-8.

12. Wang $X B$, Zhao X, Giscombe R, Lefvert AK. A CTLA-4 gene polymorphism at position -318 in the promoter region affects the expression of protein. Genes Immun 2002; 3: 233-234.

13. Ueda H, Howson JM, Esposito L, Heward J, Snook H, Chamberlain $\mathrm{G}$, et al. Association of the T-cell regulatory gene CTLA4 with susceptibility to autoimmune disease. Nature 2003; 423: 506-511.

14. Vaidya $B$, Pearce $S$. The emerging role of the CTLA-4 gene in autoimmune endocrinopathies. Eur J Endocrinol 2004; 150: 619626.

15. Barreto M, Santos E, Ferreira R, Fesel C, Fontes MF, Pereira C, et al. Evidence for CTLA4 as a susceptibility gene for systemic lupus erythematosus. Eur J Hum Genet 2004; 12: 620-626.

16. Becker KG, Simon RM, Bailey-Wilson JE, Freidlin B, Biddison WE, McFarland HF, et al. Clustering of non-major histocompatibility complex susceptibility candidate loci in human autoimmune diseases. Proc Natl Acad Sci U S A 1998; 95: 9979-9984.

17. Kristiansen OP, Larsen ZM, Pociot F. CTLA-4 in autoimmune diseases - a general susceptibility gene to autoimmunity? Genes Immun 2000; 1: 170-184.

18. Bonetti A, Reunanen K, Finnila S, Koivisto K, Wikstrom J, Sumelahti $\mathrm{ML}$, et al. A two-stage study on multiple sclerosis susceptibility and chromosome 2q33. Genes Immun 2004; 5: 142-146.

19. Miterski B, Drynda S, Boschow G, Klein W, Oppermann J, Kekow J, et al. Complex genetic predisposition in adult and juvenile rheumatoid arthritis. BMC Genet 2004; 5: 2.

20. Schneider RF, Roessli D, Excofier L. ARLEQUIN: a software for population genetic data analysis, version 2000. [Computer program]. Department of Anthropology, University of Genève, Genève: Genetics and Biometry Laboratories; 2000.

21. Miller MP. RxC: A program for the analyses of contingency tables via the Metropolis Algorithm. Computer software distributed by the author; 1997.

22. Harper K, Balzano C, Rouvier E, Mattei MG, Luciani MF, Golstein P. CTLA-4 and CD28 activated lymphocyte molecules are closely related in both mouse and human as to sequence, message expression, gene structure, and chromosomal location. J Immunol 1991; 147: 1037-1044.

23. Deichmann K, Heinzmann A, Bruggenolte E, Forster J, Kuehr J. An Mse I RFLP in the human CTLA4 promotor. Biochem Biophys Res Commun 1996; 225: 817-818.

24. Donner H, Seidl C, Braun J, Siegmund T, Herwig J, Seifried E, et al. CTLA4 gene haplotypes cannot protect from IDDM in the presence of high-risk HLA DQ8 or DQ2 alleles in German families. Diabetes 1998; 47: 1158-1160.

25. Gonzalez-Escribano MF, Rodriguez R, Valenzuela A, Garcia A, Garcia-Lozano JR, Nunez-Roldan A. CTLA4 polymorphisms in Spanish patients with rheumatoid arthritis. Tissue Antigens 1999; 53: 296-300.

26. Braun J, Donner H, Siegmund T, Walfish PG, Usadel KH, Badenhoop K. CTLA-4 promoter variants in patients with Graves' disease and Hashimoto's thyroiditis. Tissue Antigens 1998; 51: 563-566. 